\title{
BMJ Global Health Inverse correlates of COVID-19 mortality across European countries during the first versus subsequent waves
}

\author{
Leonardo Villani (D) , ${ }^{1}$ Roberta Pastorino, ${ }^{2}$ Walter Ricciardi, ${ }^{1}$ John loannidis (D) ,3,4 \\ Stefania Boccia ${ }^{1,2}$
}

To cite: Villani L, Pastorino R, Ricciardi W, et al. Inverse correlates of COVID-19 mortality across European countries during the first versus subsequent waves. BMJ Global Health 2021;6:e06422. doi:10.1136/ bmjgh-2021-006422

Handling editor Seye Abimbola

- Additional supplemental material is published online only. To view, please visit the journal online (http://dx.doi.org/10. 1136/bmjgh-2021-006422)

LV and RP contributed equally. $\mathrm{SB}$ and Jl contributed equally.

Received 26 May 2021

Accepted 14 July 2021

\section{ABSTRACT}

The objectives of the study were to calculate the standardised mortality rates (SMRs) for COVID-19 in European Union/European Economic Area countries plus the UK and Switzerland and to evaluate the correlation between SMRs and selected indicators in the first versus the subsequent waves until 23 June 2021. We used indirect standardisation (using Italy as the reference) to compute SMRs and considered 16 indicators of health and social well-being, health system capacity and COVID-19 response. The highest SMRs were in Belgium, the UK and Spain in the first wave (1.20-1.84) and in Hungary, Czechia and Slovakia in the subsequent waves (2.50-2.69). Human Development Index (HDI), life expectancy, urbanisation and healthcare expenditure had positive correlations with SMR in the first wave (rho $=0.30-0.46$ ), but negative correlations (rho $=-0.67$ to -0.47 ) in the subsequent waves. Retail/ recreation mobility and transit mobility were negatively correlated with SMR in the first wave, while transit mobility was inversely correlated with SMR in the subsequent waves. The first wave hit most hard countries with high $\mathrm{HDI}$, high life expectancy, high urbanisation, high health expenditures and high tourism. This pattern may reflect higher early community seeding and circulation of the virus. Conversely, in the subsequent waves, this pattern was completely inversed: countries with more resources and better health status did better than eastern European countries. While major SMR differences existed across countries in the first wave, these differences largely dissipated by 23 June 2021, with few exceptions.

\section{INTRODUCTION}

European countries have been highly affected by the COVID-19 pandemic. Since the beginning of the pandemic in February 2020 and as of the second half of June 2021, SARS-CoV-2 had been linked to almost 1 million deaths in the European Union/European Economic Area (EU/EEA), with a crude mortality rate (CMR) of around 1.6 per 1000 inhabitants. ${ }^{1}$ The pattern of the pandemic has varied across countries, but a common feature across Europe has been the presence of a first wave occurring in the spring of 2020 followed by a consistent reduction in the spread of the virus

\section{Key questions}

What is already known?

- Since the onset of the COVID-19 pandemic in early 2020 , several studies have been conducted investigating pandemic trends in terms of deaths and crude mortality rates.

What are the new findings?

- It is known that mortality from COVID-19 increases with age and it is higher in patients with comorbidities.

What do the new findings imply?

- The lack of age-stratified data makes comparison across countries difficult. Therefore, evidence on the impact of COVID-19 on mortality remains limited.

in the summer and a resumption of epidemic activity in the fall of 2020 with second and/ or third waves. ${ }^{2}$ Therefore, it is possible to identify two major phases of SARS-CoV-2 spread which here we call for consistency, the first and subsequent waves. These two phases had a different impact in different European countries. In the first phase, indeed, Italy was the original epicentre of the pandemic in Europe, ${ }^{3}$ with a subsequent spread in several western European countries (mainly the UK, Sweden, Spain, France, Belgium, Germany), while eastern Europe was less affected by the virus. As of fall 2020, in addition to the re-emerging wave in the western European countries, an increase in cases and consequently in deaths has been observed in eastern Europe (especially Hungary, Czechia and Slovakia). A key question, therefore, is whether there are factors that have favoured the different spread of the virus and the related deaths among countries and between the first and subsequent waves in the same countries.

It is known that mortality from COVID-19 increases with age and it is higher in patients 
with comorbidities. ${ }^{4-6}$ Other factors, however, may have influenced the different mortality rates in countries, explaining, at least in part, these differences. In addition to the different COVID-19 responses adopted, which include containment measures, mandatory face covering, the testing, trace and isolation capabilities, and to the pre-existing availability of hospital beds, ${ }^{7}$ other social, demographic and economic factors might explain the different mortality rates in Europe.

Therefore, the aim of our study was to compare the standardised mortality rates (SMRs) of EU/EEA countries plus the UK and Switzerland between the first and subsequent waves of the pandemic and to evaluate the correlation patterns between SMRs and selected indicators including sociodemographic and health status variables, availability of healthcare resources and facilities and COVID-19 response in the first versus the subsequent waves.

\section{METHODS}

\section{Comparison of standardised mortality rate of COVID-19 in first versus subsequent waves}

We obtained the absolute number of COVID-19 deaths in each EU/EEA country plus the UK and Switzerland as of 23 June 2021, from the Our World in Data database. $^{8}$ The UK and Switzerland were included because of geographical proximity, similar sociocultural factors and data availability.

Given the lack of data on age groups of deaths by COVID-19 in many countries, we used indirect standardisation, ${ }^{9}$ with Italy as the standard population. We calculated the CMR for COVID-19 in Italy for each age categories $(0-9,10-19,20-29,30-39,40-49,50-59$, $60-69,70-79$ and $\geq 80)$, and subsequently, we calculated the expected deaths in each country and the SMR of each country. Specifically, to calculate the expected deaths, we multiplied the Italian CMR of each age group by the population of that age group of the country under study. Total expected deaths are given by the sum of expected deaths for each age group. Therefore, the SMR is given by the ratio of the observed deaths in the country under study by the total expected deaths.

SMRs were calculated overall (as of 23 June 2021, corresponding to the last available report of the Italian National Institute of Health) ${ }^{10}$ and separately for the first and subsequent waves, with their $95 \%$ CI.

Concerning the identification of the two waves, we referred to the end of the first wave in Italy using the date between the two peaks that had the trough (lowest number of deaths) for a 7-day average. ${ }^{2}$

The end of the first wave, thus, was set at 18 August 2020.

Finally, in order to assess the impact of potential different undercounting/overcounting of COVID-19 deaths across countries in the overall period (through 23 June 2021), we compared the 0-69 years age group SMR with all ages SMR. Countries may differ on how they count deaths for elderly individuals, especially in nursing homes and those dying at home, while documentation may be more standard in non-elderly people. In particular, we obtained age-stratified data for 16 countries $^{11-14}$ for which we calculated the SMR of the 0-69 years age group using Italy as the reference country.

\section{Correlation between SMRs and selected indicators}

We considered three groups of indicators in relation to the different dimensions of (1) health and social wellbeing (sociodemographic and health status), (2) the health system capacity (healthcare resources and facilities) and (3) the COVID-19 response, totaling for 16 indicators. In particular, we obtained data from the Eurostat Database, the United Nations Database, the World Bank, the European Observatory on Health Systems and Polices, the Organisation for Economic Co-operation and Development (OECD) and the scientific literature. ${ }^{15-21}$ Online supplemental table S1 reports the definition of each indicator and the data source. Online supplemental tables S2 and S3 show the data for each indicator.

The first group of indicators includes the Human Development Index (HDI), the life expectancy at birth, the percentage of people at risk of poverty and social exclusion, the healthy life years (HLY), the population density and the percentage of urbanisation.

As for the health system capacity, we considered the number of hospital beds per 1000 inhabitants and the number of intensive care units (ICU) beds per 1000 inhabitants and the proportion of health expenditure on the total gross domestic product.

Finally, we included the average value of the Stringency Index (SI) (it is a composite measure based on nine indicators including school, workplace and public transport closures, cancellation of public events, restrictions on public gatherings, stay-at-home requirements, public information campaigns, restrictions on internal movements and international travel controls), the average of the variation of mobility (retail and recreation, transit, outdoor), the test capacity (total tests done per 1000 inhabitants and the average of new tests done per 1000 inhabitants) and the variation of number of tourists, as indicators of COVID-19 response. Specifically, for each country, we averaged the values of the first and subsequent waves (from the beginning of the pandemic to 18 August 2020 and from 19 August 2020 to 23 June 2021, respectively) for SI, mobility variation and test capacity. Considering the variation of number of tourists, for each country, we calculated this indicator in the early period of the first (sum of March and April 2020, adjusted per million) and the subsequent waves (sum of August and September 2020, adjusted per million).

\section{STATISTICAL ANALYSES}

We analysed the correlation between SMRs in the first and in the subsequent waves and the correlation between the SMRs and all the selected indicators, separately for 
the first and subsequent waves, using the Spearman's rank correlation coefficient with $95 \%$ bootstrapping CI. We compared the correlations calculated in the first and subsequent waves with the test of the difference between two independent correlation coefficients. ${ }^{22}$

As an exploratory analysis, a tree-building technique called classification and regression tree (CART) analysis was applied to select the indicators and cut-offs thereof that would best describe groups of countries with different SMRs, separately in the first and subsequent waves. The indicators included and analysed in the regression tree were selected from the group of indicators found to be correlated with SMRs. $\mathrm{P}$ values $<0.005$ were considered statistically significant. ${ }^{23}$ All statistical analyses were performed using Stata software, V.16 (StataCorp LP, College Station, Texas), and R software, V.R.4.0.5 (package rpart).

\section{RESULTS}

\section{SMRs in first and subsequent waves}

As of 23 June 2021, the SMRs for COVID-19 varied greatly across the 31 countries under study (range from 0.07 of Iceland to 1.97 of Hungary, table 1). Overall, 11 countries had an SMR $>1$, while 19 countries had an overall $\mathrm{SMR}<1$ compared with Italy, with the highest SMRs in

Table 1 Standardised mortality rates (SMRs) for COVID-19 in the European Union/European Economic Area countries plus the UK and Switzerland

\begin{tabular}{|c|c|c|c|c|c|}
\hline Country & Abbreviation & First wave & Subsequent waves & Variation first/subsequent waves & Overall \\
\hline Austria & AT & 0.17 & 0.93 & 0.76 & 0.72 \\
\hline Belgium & $\mathrm{BE}$ & 1.80 & 1.08 & -0.72 & 1.28 \\
\hline Bulgaria & $B G$ & 0.15 & 2.07 & 1.92 & 1.52 \\
\hline Croatia & HR & 0.08 & 1.58 & 1.50 & 1.15 \\
\hline Cyprus & CY & 0.06 & 0.42 & 0.36 & 0.32 \\
\hline Czechia & $\mathrm{CZ}$ & 0.09 & 2.57 & 2.48 & 1.87 \\
\hline Denmark & DK & 0.23 & 0.29 & 0.06 & 0.27 \\
\hline Estonia & $\mathrm{EE}$ & 0.10 & 0.73 & 0.63 & 0.55 \\
\hline Finland & $\mathrm{FI}$ & 0.12 & 0.09 & -0.03 & 0.10 \\
\hline France & FR & 0.89 & 0.93 & 0.04 & 0.92 \\
\hline Germany & DE & 0.20 & 0.69 & 0.49 & 0.55 \\
\hline Greece & EL & 0.04 & 0.79 & 0.75 & 0.58 \\
\hline Hungary & $\mathrm{HU}$ & 0.14 & 2.69 & 2.55 & 1.97 \\
\hline Iceland & IS & 0.08 & 0.06 & -0.02 & 0.07 \\
\hline Ireland & IE & 1.06 & 0.76 & -0.30 & 0.84 \\
\hline Italy* & IT & 1 & 1 & - & 1 \\
\hline Latvia & LV & 0.03 & $1.01 \dagger$ & 0.98 & 0.73 \\
\hline Lithuania & LT & 0.05 & 1.21 & 1.16 & 0.88 \\
\hline Luxemburg & LU & 0.55 & 1.21 & 0.66 & $1.02 \dagger$ \\
\hline Malta & MT & 0.04 & 0.76 & 0.72 & 0.55 \\
\hline Netherlands & NL & 0.79 & 0.59 & -0.20 & 0.65 \\
\hline Norway & NO & 0.12 & 0.10 & -0.02 & 0.10 \\
\hline Poland & $P L$ & 0.12 & 1.82 & 1.70 & 1.34 \\
\hline Portugal & PT & 0.31 & 1.06 & 0.75 & 0.85 \\
\hline Romania & RO & 0.36 & 1.37 & 1.01 & 1.08 \\
\hline Slovakia & SK & 0.02 & 2.50 & 2.48 & 1.80 \\
\hline Slovenia & SI & 0.13 & 1.67 & 1.54 & 1.23 \\
\hline Spain & ES & 1.20 & 0.86 & -0.34 & 0.96 \\
\hline Sweden & SE & 1.18 & 0.71 & -0.47 & 0.85 \\
\hline Switzerland & $\mathrm{CH}$ & 0.50 & 0.88 & 0.38 & 0.77 \\
\hline United Kingdom & UK & 1.39 & 1.16 & -0.23 & 1.22 \\
\hline
\end{tabular}

*Standard population.

†SMR not significant different from 1. 


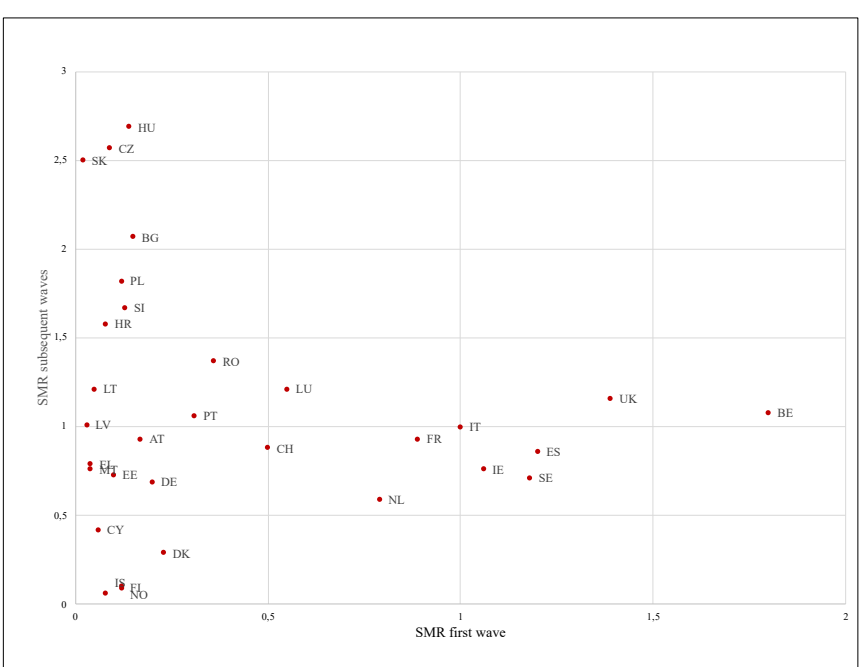

Figure 1 Relationship between the SMRs for COVID-19 of the first versus the subsequent waves in the EU/EEA countries plus UK and Switzerland.

Hungary, Czechia and Slovakia. According to the waves, the highest SMRs were in Belgium, the UK and Spain in the first wave $\left(\mathrm{SMR}_{\mathrm{BE}}=1.80 ; \mathrm{SMR}_{\mathrm{UK}}=1.39 ; \mathrm{SMR}_{\mathrm{ES}}=1.20\right)$, while in the subsequent waves the highest SMRs were from Hungary, Czechia and Slovakia $\left(\mathrm{SMR}_{\mathrm{HU}}=2.69\right.$, $\mathrm{SMR}_{\mathrm{CZ}}=2.57 ; \mathrm{SMR}_{\mathrm{SK}}=2.50$ ) (table 1). Slovakia, Latvia and Malta reported the lowest values in the first wave $\quad\left(\mathrm{SMR}_{\mathrm{SK}}=0.02 ; \quad \mathrm{SMR}_{\mathrm{LV}}=0.03 ; \quad \mathrm{SMR}_{\mathrm{MT}}=0.04\right)$, while Iceland, Finland and Norway in the subsequent waves $\left(\mathrm{SMR}_{\mathrm{IS}}=0.06 ; \mathrm{SMR}_{\mathrm{FI}}=0.09 ; \mathrm{SMR}_{\mathrm{NO}}=0.10\right)$. Overall, 12 countries (Bulgaria, Croatia, Czechia, Hungary, Latvia, Lithuania, Luxemburg, Poland, Portugal, Romania, Slovakia, Slovenia) moved from an $\mathrm{SMR}<1$ in the first wave to an SMR $>1$ in the subsequent wave. On the contrary, three countries (Ireland, Spain and Sweden) moved from an $\mathrm{SMR}>1$ in the first wave to an $\mathrm{SMR}<1$ in the subsequent waves (table 1). Countries reporting the highest variation between the two waves of COVID-19 were Hungary, Czechia and Slovakia with low SMRs in the first wave and high in the subsequent waves and Belgium, Spain, and Sweden in the opposite direction (table 1). Iceland, Norway and Finland reported the lowest variation of the SMRs between the two waves. Figure 1 reports the relationship between the SMRs of the first versus the subsequent waves. No correlation exists between the two waves $($ rho $=-0.06 ; \mathrm{p}=0.75)$.

\section{Correlates of SMRs in first versus subsequent waves}

The correlations between SMRs and the sociodemographic and health status variables, the healthcare resources and facilities and the COVID-19 response are summarised in table 2 separately for the first and subsequent waves, along with the test of the difference between the two coefficients.

Several variables had inverse correlations with SMRs in the first versus the subsequent waves. The difference in the first versus the subsequent waves was stark and reached $\mathrm{p}<0.005$ for the comparison of the two correlation coefficients for HDI, life expectancy, urbanisation and healthcare expenditure. These variables had positive correlations with SMR in the first wave $(\mathrm{rho}=0.30-0.49)$, but negative correlations with SMR (rho $=-0.67$ to -0.47 ) in the subsequent waves. Of the variables that reflected the response to COVID-19, two mobility variables (retail/ recreation and transit) were negatively correlated with SMR in the first wave, that is, countries that were more hit had smaller mobility. In the subsequent waves, conversely, transit mobility was correlated with SMR, but the correlation had been inversed (countries that were most hit had higher mobility). Finally, tourism had a positive correlation with SMR $(\mathrm{rho}=0.52)$ in the first wave, but no correlation in the subsequent waves.

\section{SMR in the 0-69 years age group}

Figure 2 shows the correlation between SMRs in 0-69 years group versus all ages. There is a strong correlation (rho $=0.89, \mathrm{p}=0.001)$. However, some countries (Greece, Hungary, Poland, Romania, the UK) had worse SMR when data were limited to deaths at age 0-69 years as compared with their overall SMR picture (online supplemental table S4).

\section{CART analysis to describe countries with different SMRs}

In the first wave (figure 3), exploratory CART analysis produced an optimal tree structure of three terminal nodes. The lowest SMR (0.13) was seen in countries that paradoxically did not have much reduction in their transit mobility and that did not have high health expenditure. SMR was modest (0.36) for countries that did not have much reduction in their transit mobility and had health expenditure $>9 \%$. Finally, SMR was highest (1.10) in countries that reduced their transit mobility by $35 \%$ or more (Belgium, France, Ireland, the Netherlands, Portugal, Spain and the UK).

Concerning the subsequent waves (figure 4), the pattern was inversed. The worse SMR (1.8) was seen in countries without high life expectancy ( $<80$ years). Among countries with life expectancy of 80 years or more, moderate SMR (0.99) was seen in those that had $\mathrm{HDI}<0.95$ and the lowest SMR (0.46) was seen in nine countries with high HDI $\geq 0.94$ (Denmark, Finland, Germany, Iceland, Ireland, the Netherlands, Norway, Sweden, Switzerland).

\section{DISCUSSION}

Our study compared the age standardised COVID-19 mortality rates of 31 European countries in relation to variables reflecting the health and social well-being, the health system capacity and the pandemic response. Standardisation of mortality rates can help to understand better whatever differences exist between countries, as it provides an adjusted figure of mortality rates that takes into account the different age structures of the compared populations. ${ }^{24}$ We found that SMRs in the first wave were not correlated with SMRs in the later phase of the pandemic. This means that good performance during the first wave did not predict whether a country did good 
Table 2 Correlation between the standardised mortality rates for COVID-19 in the European Union/European Economic Area countries plus the UK and Switzerland and selected indicators

\begin{tabular}{|c|c|c|c|c|c|}
\hline Variable & $\begin{array}{l}\text { First wave } \\
\text { Spearman's rho } \\
\text { correlation }(95 \% \mathrm{Cl})\end{array}$ & $P$ value & $\begin{array}{l}\text { Subsequent waves } \\
\text { Spearman's rho } \\
\text { correlation }(95 \% \mathrm{Cl})\end{array}$ & $P$ value & $\begin{array}{l}P \text { value of the difference } \\
\text { between first and } \\
\text { subsequent waves }\end{array}$ \\
\hline HDI & $0.41(0.14$ to 0.68$)$ & 0.02 & $-0.67(-0.87$ to -0.46$)$ & $<0.0001$ & 0.000003 \\
\hline $\begin{array}{l}\text { Life expectancy at } \\
\text { birth }\end{array}$ & $0.46(0.14$ to 0.77$)$ & 0.01 & $-0.56(-0.79$ to -0.33$)$ & 0.001 & 0.00002 \\
\hline $\begin{array}{l}\text { Poverty and social } \\
\text { exclusion }\end{array}$ & $0.04(-0.32$ to 0.41$)$ & 0.82 & $0.25(-0.15$ to 0.66$)$ & 0.17 & 0.42 \\
\hline HLY & $0.36(-0.02$ to 0.73$)$ & 0.05 & $-0.20(-0.54$ to 0.13$)$ & 0.27 & 0.03 \\
\hline Density & $0.33(-0.03$ to 0.68$)$ & 0.07 & $0.17(-0.24$ to 0.57$)$ & 0.37 & 0.52 \\
\hline Urbanisation & $0.30(-0.06$ to 0.67$)$ & 0.10 & $-0.51(-0.77$ to -0.24$)$ & 0.004 & 0.0011 \\
\hline Hospital beds* & $-0.28(-0.62$ to 0.06$)$ & 0.13 & - & - & - \\
\hline ICU beds* & $-0.16(-0.48$ to 0.15$)$ & 0.38 & - & - & - \\
\hline $\begin{array}{l}\text { Healthcare } \\
\text { expenditure }\end{array}$ & $0.49(0.22$ to 0.76$)$ & 0.005 & $-0.47(-0.70$ to -0.24$)$ & 0.008 & 0.00009 \\
\hline Stringency Index & 0.40 (0.09 to 0.70$)$ & 0.03 & $-0.03(-0.40$ to 0.33$)$ & 0.85 & 0.09 \\
\hline $\begin{array}{l}\text { Mobility retail and } \\
\text { recreation }\end{array}$ & $\begin{array}{l}-0.51(-0.86 \text { to } \\
-0.15)\end{array}$ & 0.005 & $-0.31(-0.68$ to 0.06$)$ & 0.10 & 0.38 \\
\hline Mobility transit & $\begin{array}{l}-0.66(-0.90 \text { to } \\
-0.43)\end{array}$ & 0.0001 & $0.50(0.17$ to 0.83$)$ & 0.006 & 0.000001 \\
\hline Mobility outdoor & $\begin{array}{l}-0.40(-0.72 \text { to } \\
-0.07)\end{array}$ & 0.03 & $-0.37(-0.72$ to -0.03$)$ & 0.05 & 0.90 \\
\hline Total tests per 1000 & $0.16(-0.22$ to 0.54$)$ & 0.42 & $-0.24(-0.63$ to 0.16$)$ & 0.22 & 0.15 \\
\hline New tests per 1000 & $0.24(-0.16$ to 0.64$)$ & 0.22 & $-0.25(-0.69$ to 0.20$)$ & 0.22 & 0.94 \\
\hline Tourism & $0.52(0.21$ to 0.83$)$ & 0.004 & $0.07(-0.29$ to 0.44$)$ & 0.71 & 0.07 \\
\hline
\end{tabular}

Bold values denote statistical significance at the $p \leq 0.005$ level.

${ }^{*}$ Data were not available for the subsequent waves.

HDI, Human Development Index; HLY, healthy life years; ICU, intensive care units.

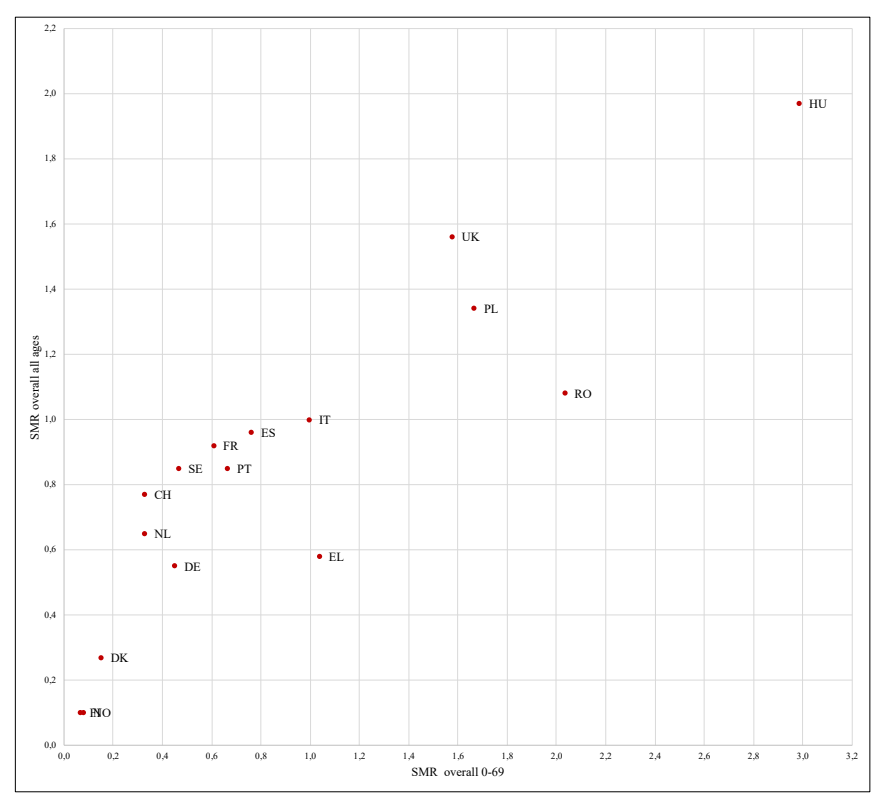

Figure 2 Relationship between the overall SMRs for COVID-19 of the 0-69 group versus all ages group in $16 \mathrm{EU} /$ EEA countries. or poorly in the subsequent waves. We also found that the variables that were most strongly correlated with SMR had inverse correlations in the two waves.

The first wave hit most hard countries with high HDI, high life expectancy, high urbanisation and high health

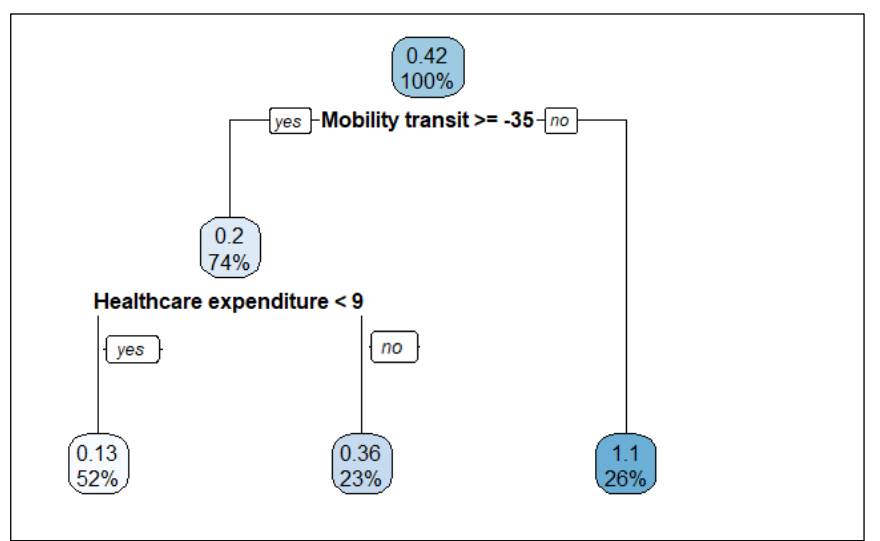

Figure 3 Regression tree diagram in prediction of SMR from the socio-demographic and health status, healthcare resources and facilities, and the COVID-19 response indicators in the first wave. 


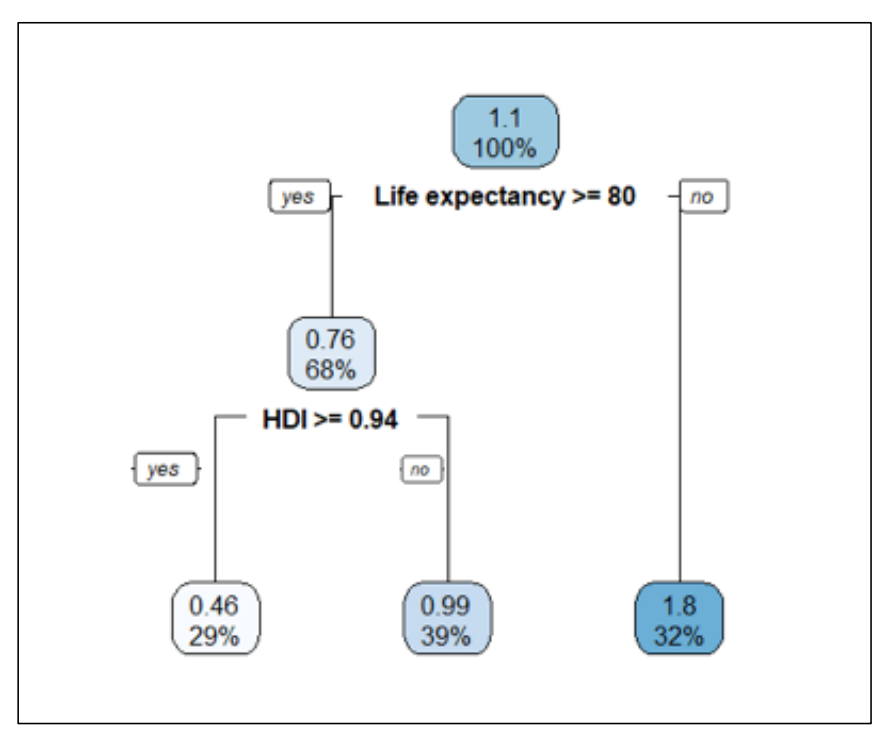

Figure 4 Regression tree diagram in prediction of SMR from the socio-demographic and health status, healthcare resources and facilities, and the COVID-19 response indicators in the subsequent waves.

expenditures. Conversely, in the subsequent waves, these countries did better in handling the death toll from the epidemic wave. These variables are all correlated with each other and, therefore, it is difficult to pinpoint which one of them is most important. HDI includes life expectancy in its definition, and countries with higher HDI also tend to be more urbanised and spend more on health. These countries are also likely to have had some other features that are not easy to measure but which predisposed to a worse outcome during the first wave. In particular, these countries are likely to have had higher seeding of the virus from abroad and also larger dispersion of the virus across their open boundaries and highly active economic life before the pandemic became recognised and measures were taken. The additional strong correlation of SMR with higher tourism volume in March and April 2020 is also congruent with higher seeding. Conversely, countries with lower HDI, lower life expectancy, lower urbanisation and lower tourism volume probably faced a lesser challenge, with lower seeding burden of SARS-COV-2 and they managed to keep the virus as bay despite more limited resources and, on average, less prepared healthcare systems.

In the fall of 2020 when a new COVID-19 wave hit, the circumstances were inversed. Countries with higher HDI, longer life expectancy and spending more on health were probably better prepared to handle the new epidemic wave. Conversely, other countries did more poorly in this phase and some of them also had the worst performance overall when the entire pandemic period is considered. This is particularly true of eastern European countries (eg, Hungary, Czechia, Slovakia and Bulgaria).$^{25}$ Of note, some eastern European countries also have high overall population mortality rates (crude death rates) on any average year irrespective of COVID-19. For example, the overall population mortality for Bulgaria is the highest in the world (15.4 per thousand) and most other eastern European countries have values exceeding 10 per thousand. ${ }^{26}$ Moreover, HDI and life expectancy present lower values in the countries of eastern Europe (Bulgaria has the lowest values among the EU/EEA countries). Similarly, these countries have a lower healthcare expenditure and the greater degree of poverty and social exclusion. Countries with a more disadvantaged profile may have been less able to respond to the crisis. We had no reliable information on hospital beds and ICU beds during the subsequent waves and data from before the first wave would be unwise to use, because many countries urgently upgraded their bed capacity in anticipation of escalating crisis. Moreover, information on number of beds does not suffice to give a good picture of the preparedness and functionality of a health system.

Of note, while differences in SMR across countries were huge in the first wave (sometimes in the range of 20-100-fold), differences in SMR across countries for the overall pandemic experience shrank a lot by 23 June 2021. By that time, only five countries managed to retain $\mathrm{SMR} \leq 0.35$ compared with Italy, which was used as the reference country. These five countries (Norway, Iceland, Finland, Denmark and Cyprus) have managed to contain the pandemic extremely effectively. It is difficult to say conclusively which the common denominator of their success is. All five performed aggressive testing with large numbers of tests done despite relatively low levels of detected cases. We found no correlation between testing and SMR when all European countries were considered, but the number of tests done reflects not only the aggressiveness of testing but also-mostly-the volume of people who seek testing and this is proportional to the epidemic burden. Two of these five countries are also islands, and like Australia and New Zealand in Oceania, ${ }^{27}{ }^{28}$ they had the ability to control and close influx of travel in the early phase of the pandemic, while this was impossible to do as easily for most of the continental European countries. Many other explanations of success may be invoked, but they should all be cautious since one can easily fall into the fallacy of interpreting or overinterpreting sporadic data points. Moreover, as of this writing, the pandemic is still not over. Therefore, it cannot be excluded that further convergence of overall SMRs across different countries may happen in the future.

Correlations with mobility indicators are interesting to discuss, because they also showed inverse patterns between the first and subsequent waves. Reverse causality (more epidemic burden leading to more reduction of mobility) may be responsible for the paradoxical positive correlation between more mobility and lower SMR in the first wave. The correlation pattern was entirely reversed for retail and recreation mobility in the subsequent waves. Reduction in mobility is expected to lead to reduced exposures and thus decreased burden of the epidemic wave. However, not all reduction has the same impact on exposures and some reduction in mobility may even generate genuinely harmful effects, for example, if 
it leads to more clustering of people segregated in more limited space for longer periods of time. One should be very cautious and avoid making inferences on mobility effects from ecological data. This same limitation applies even more to associations related to aggregate indicators of measures, such as the stringency indicator.

Several other limitations should be discussed in this work. First, the core of our study used ecological analyses and therefore one should be cognizant of the risk of ecological fallacy. We advise great caution in trying to make causal inferences from ecological variables. The fact that the correlations were inversed in the two time periods further demonstrates this point. The observed patterns should be seen in their totality, as hints for some factors that may or may not be possible to measure and which may explain these correlations. The same applies to the exploratory CART analyses that aimed to describe these patterns rather than attribute causality. Second, our analysis makes no claim of trying to probe the impact of policy or other measures taken to diminish the case load and resulting deaths. There is major debate in the literature about the merits of different measures ${ }^{29-33}$ and ecological analyses would be a very weak design to study the effects of different non-pharmaceutical measures. Third, despite some efforts of standardisation of COVID-19 death definition, ${ }^{34}$ different countries may have captured COVID-19 differently and this may have resulted both in overcounting and undercounting of deaths. ${ }^{35} 36$ For example, countries that ascribe more deaths of nursing home residents and of palliative care patients to COVID-19 would tend to have higher SMR estimates, even though their true death burden and lost person-years may not have been that high. Differential overcounting and undercounting may be more common and more diverse across countries in the elderly age groups. Analyses excluding deaths in the elderly yielded nevertheless SMRs that correlated substantially with those of all-age SMRs, but some countries in eastern Europe, Greece and the UK appeared to do much worse when analyses were limited to the non-elderly. Detailed availability of age and comorbidity information across all countries would allow hopefully performing in the future more granular analyses of the relative disease burden of COVID-19.

\section{CONCLUSION}

To our knowledge, this is the first study that standardises mortality rates across European countries, allowing a better understanding of the differences between countries. Indeed, the analysis of SMRs shows a different evolution of the pandemic, especially comparing eastern and western European countries. In particular, the first wave hit most hard countries with high HDI, high life expectancy, high urbanisation, high health expenditure and high tourism, and this pattern may reflect a higher early community seeding and circulation of the virus. In the subsequent waves, instead, this pattern was completely inversed: countries with more resources and better health status did better than eastern European countries. Finally, while major SMR differences existed across countries in the first wave, these differences largely dissipated by 23 June 2021, with few exceptions.

\section{Author affiliations}

${ }^{1}$ Section of Hygiene, University Department of Life Sciences and Public Health, Università Cattolica del Sacro Cuore, Rome, Italy

${ }^{2}$ Department of Woman and Child Health and Public Health - Public Health Area, Fondazione Policlinico Universitario A. Gemelli IRCCS, Rome, Italy

${ }^{3}$ Stanford Prevention Research Center, Department of Medicine, and Department of Epidemiology and Population Health, Stanford University School of Medicine,

Stanford, CA, USA

${ }^{4}$ Meta-Research Innovation Center at Stanford, (METRICS), Stanford, CA, USA

Acknowledgements The authors would like to thank Angelo Maria Pezzullo, Section of Hygiene, University Department of Life Sciences and Public Health, Università Cattolica del Sacro Cuore, Rome, Italy, for his help in COVID-19 deaths by age data collection.

Contributors All authors contributed to the study conception and design. Material preparation and data collection were performed by LV, RP and JI. Authors RP and LV performed the statistical analysis. The first draft of the manuscript was written by all authors. Authors JI, WR and SB commented on the subsequent and latest version of the manuscript. Jl and SB supervised the work. All authors have read and agreed to the published version of the manuscript.

Funding The authors have not declared a specific grant for this research from any funding agency in the public, commercial or not-for-profit sectors.

Competing interests None declared.

\section{Patient consent for publication Not required.}

Provenance and peer review Not commissioned; externally peer reviewed.

Data availability statement All data relevant to the study are included in the article or uploaded as supplementary information. All data were collected from International Data Base. We obtained data from the Eurostat Database, the United Nations Database, the World Bank, the European Observatory on Health Systems and Polices, the Organisation for Economic Co-operation and Development, the Our World in Data database and the scientific literature.

Supplemental material This content has been supplied by the author(s). It has not been vetted by BMJ Publishing Group Limited (BMJ) and may not have been peer-reviewed. Any opinions or recommendations discussed are solely those of the author(s) and are not endorsed by BMJ. BMJ disclaims all liability and responsibility arising from any reliance placed on the content. Where the content includes any translated material, BMJ does not warrant the accuracy and reliability of the translations (including but not limited to local regulations, clinical guidelines, terminology, drug names and drug dosages), and is not responsible for any error and/or omissions arising from translation and adaptation or otherwise.

Open access This is an open access article distributed in accordance with the Creative Commons Attribution Non Commercial (CC BY-NC 4.0) license, which permits others to distribute, remix, adapt, build upon this work non-commercially, and license their derivative works on different terms, provided the original work is properly cited, appropriate credit is given, any changes made indicated, and the use is non-commercial. See: http://creativecommons.org/licenses/by-nc/4.0/.

\section{ORCID iDs}

Leonardo Villani http://orcid.org/0000-0001-9375-8731

John loannidis http://orcid.org/0000-0003-3118-6859

\section{REFERENCES}

1 European Centre for Disease Prevention and Control (ECDC). Data on the daily number of new reported COVID-19 cases and deaths by EU/EEA country, 2021.

2 loannidis JPA, Axfors C, Contopoulos-loannidis DG. Second versus first wave of COVID-19 deaths: shifts in age distribution and in nursing home fatalities. Environ Res 2021;195:110856.

3 Remuzzi A, Remuzzi G. COVID-19 and Italy: what next? The Lancet 2020;395:1225-8.

4 Onder G, Rezza G, Brusaferro S. Case-Fatality rate and characteristics of patients dying in relation to COVID-19 in Italy. JAMA 2020;323:1775-6.

5 loannidis JPA, Axfors C, Contopoulos-loannidis DG. Populationlevel COVID-19 mortality risk for non-elderly individuals overall and 
for non-elderly individuals without underlying diseases in pandemic epicenters. Environ Res 2020;188:109890.

6 Wang B, Li R, Lu Z. Does comorbidity increase the risk of patients with COVID-19. Aging 2020;12:6049-57.

7 European Observatory on health systems and policies. COVID-19 health system response monitor - cross-country analysis, 2021.

8 Our World in Data. COVID-19 Data Explorer [Internet], 2021. Available: https://ourworldindata.org/explorers/coronavirusdata-explorer?zoomToSelection=true\&time $=2020-03-01$.latest\& pickerSort=asc\&pickerMetric=location\&Metric $=$ Confirmed + deaths\&Interval=Cumulative\&Relative+to+Population=true\&Align+ outbreaks=false

9 Naing NN. Easy way to learn standardization : direct and indirect methods. Malays J Med Sci 2000;7:10-15.

10 Italian National Institute of Health. COVID-19 epidemic. 23 June 2021 national update. 2021.

11 Institut national d'études démographiques (INED). The demography of COVID-19 deaths [Internet]. Available: https://dc-covid.site.ined. fr/en/

12 Riffe T, Acosta E. A database of age-structured COVID-19 cases and deaths 2020;49.

13 Polish Ministry of Health. COVID-19 death statistics [Internet]. Available: https://basiw.mz.gov.pl/index.html\#/visualization?id=3653

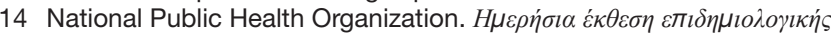

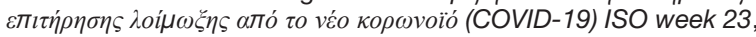
2021.

15 European Commission. Eurostat Database - Your key to European statistics [Internet], 2021. Available: https://ec.europa.eu/eurostat/ data/database

16 United Nations. Human development report - human development index and its components, 2020.

17 The World Bank. Data - Population density (people per sq. km of land area), 2020.

18 European Observatory on Health Systems and Policies. COVID-19 - The Health System Response Monitor (HSRM) [Internet], 2020. Available: https://www.covid19healthsystem.org/mainpage.aspx

19 Organization for Economic Co-operation and Development (OECD). OECD policy brief on the response to the Covid-19 crisis [Internet], 2020. Available: https://www.oecd.org/coronavirus/en/data-insights/ intensive-care-beds-capacity

20 Bauer J, Brüggmann D, Klingelhöfer D, et al. Access to intensive care in 14 European countries: a spatial analysis of intensive care need and capacity in the light of COVID-19. Intensive Care Med 2020;46:2026-34.

21 Rhodes A, Ferdinande P, Flaatten $\mathrm{H}$, et al. The variability of critical care bed numbers in Europe. Intensive Care Med 2012;38:1647-53.
22 Cohen P, Cohen P, West SG. Applied multiple regression/correlation analysis for the behavioral sciences, 2014.

23 Benjamin DJ, Berger JO, Johannesson M, et al. Redefine statistical significance. Nat Hum Behav 2018:2:6-10.

24 Villani L, McKee M, Cascini F, et al. Comparison of deaths rates for COVID-19 across Europe during the first wave of the COVID-19 pandemic. Front Public Health 2020;8:910 https://www.frontiersin. org/article/

25 United Kingdom - Office for National Statistics. Comparisons of all-cause mortality between European countries and regions, 2020. Available: https://www.ons.gov.uk/peoplepopulationandc ommunity/birthsdeathsandmarriages/deaths/articles/comparis onsofallcausemortalitybetweeneuropeancountriesandregions/ januarytojune2020

26 The World Bank. Data - Death rate, crude (per 1,000 people) [Internet]. Available: https://data.worldbank.org/indicator/SP.DYN. CDRT.IN?end=2019\&name_desc=false\&start $=1960 \&$ view $=$ chart

27 Chang SL, Harding N, Zachreson C, et al. Modelling transmission and control of the COVID-19 pandemic in Australia. Nat Commun 2020;11:1-13.

28 Adekunle A, Meehan M, Rojas-Alvarez D, et al. Delaying the COVID-19 epidemic in Australia: evaluating the effectiveness of international travel bans. Aust N Z J Public Health 2020;44:257-9.

29 Haug N, Geyrhofer L, Londei A, et al. Ranking the effectiveness of worldwide COVID-19 government interventions. Nat Hum Behav 2020:4:1303-12.

30 Flaxman S, Mishra S, Gandy A, et al. Estimating the effects of non-pharmaceutical interventions on COVID-19 in Europe. Nature 2020;584:257-61.

31 Liu Y, Morgenstern C, Kelly J, et al. The impact of nonpharmaceutical interventions on SARS-CoV-2 transmission across 130 countries and territories. BMC Med 2021;19:1-12.

32 Hsiang S, Allen D, Annan-Phan S, et al. The effect of large-scale anti-contagion policies on the COVID-19 pandemic. Nature 2020;584:262-7.

33 Bendavid E, Oh C, Bhattacharya J. Assessing mandatory stay-athome and business closure effects on the spread of COVID-19. Eur $J$ Clin Invest 2021;51.

34 World Health Organization. International guidelines for certification and classification (coding) of COVID-19 as cause of death, 2020. Available: https://www.who.int/classifications/icd/Guidelines_Cause_ of Death COVID-19.pdf?ua=1

35 loannidis JPA. Global perspective of COVID-19 epidemiology for a full-cycle pandemic. Eur J Clin Invest 2020;50:1-9.

36 loannidis JPA. Over- and under-estimaiton of COVID-19 deaths. Eur J Epidemiol. In Press 2021. 